\title{
PREVENIR A INDISCIPLINA E MELHORAR O COMPORTAMENTO DE ALUNOS EM CENTROS ESCOLARES*
}

\author{
Bela Filomena Matos ${ }^{1}$ \\ Célia Ribeiro ${ }^{2}$
}

\begin{abstract}
Resumo: Este artigo é o relato de um trabalho de investigaçãoação realizado num Centro Escolar sobre o tema da indisciplina, uma das preocupações da comunidade educativa. Direcionámos a nossa lente para os comportamentos dos alunos no recreio escolar, com incidência para os dias de chuva.

A indisciplina envolve atitudes e comportamentos que são considerados inadequados e inaceitáveis em relação ao momento, contexto ou expectativas. Para diminuir elou prevenir este fenómeno, devem ser identificadas as causas e estabelecidos programas sistemáticos de prevenção. Passa ainda pela participação de todos os agentes educativos, incluindo os alunos.

Realizámos o diagnóstico a fim de refletirmos sobre o problema, fazendo uma análise dos dados recolhidos, através de observações documentais e naturais, bem como dos questionários aplicados a pessoal docente e não docente, que nos permitiram realizar uma triangulação dos dados.

Foi elaborado e implementado um projeto na escola para ocupar de forma saudável os tempos livres, promovendo os valores e atitudes, a fim de minimizar elou prevenir os problemas de indisciplina. Pretendíamos ainda a discussão/reflexão compartilhada e a procura de soluções conjuntas. Os resultados foram positivos, com a diminuição da indisciplina e a melhoria do clima de escola, para as quais foi determinante o envolvimento da comunidade escolar e dos diferentes parceiros.

Longe de ser um "receituário" com alternativas que venham a sanar o problema, o objetivo principal do projeto foi, antes de mais,
\end{abstract}

\footnotetext{
* Este artigo é adaptado de um trabalho de projeto de Mestrado em Administração e Organização Escolar, apresentado no Centro Regional das Beiras da Universidade Católica Portuguesa, em 2015

${ }^{1}$ Docente de Educação Pré-Escolar, Mestre em Ciências da Educação, Especialização em Administração e Organização Escolar. E-mail: belafilomena@ gmail.com

2 Professora Auxiliar do Centro Regional das Beiras da Universidade Católica Portuguesa, Doutorada em Psicologia. E-mail: cribeiro@crb.ucp.pt
} 
promover a reflexão e análise do tema por parte dos envolvidos no processo educacional e dar início a um processo de mudança de atitudes dentro da escola.

Palavras-chave: indisciplina, recreio, prevenção, projeto, intervenção.

\title{
Title: PREVENT INDISCIPLINE AND IMPROVE STUDENT BEHAVIOR IN SCHOOL CENTRES
}

\begin{abstract}
This report is the result of an action research which took place at a schooling centre with the focus on the lack of discipline, one of the concerns amongst school staff. We focused our attention on student behaviour in the school playground, particularly on rainy days.

The indiscipline includes attitudes and behaviors which are considered inadequate and unacceptable considering the moment, the context or expectations. To decrease and/or prevent this phenomenon, the causes must be considered and the preventive programs established. It is also needed the participation of all the educative agents, including the students.

We made the diagnosis as a way of reflecting about the problem making an analysis of the natural data collected as well as interviews and questionnaires with teaching and non-teaching staff, so that we were able to perform a triangulation of data.

A project was developed and implemented that would occupy the students' spare time in a healthy way thereby promoting values, attitudes and ultimately minimizing and preventing disciplinary problems. We looked forward to joint discussions / brainstorming and sharing ideas in the search for better solutions. The results were positive with a decrease in indiscipline and an improvement in the schooling environment. The involvement of the school community and the different partners was a determining factor.

Far from being a "recipe" with alternatives that will solve the problem, the main objective of the project was, first of all, to promote reflection and analysis of the theme by those involved in the educational process and to initiate a process of changing attitudes inside the school.
\end{abstract}

Keywords: indiscipline, playground, prevention, project, intervention. 


\title{
INTRODUÇÃO
}

\begin{abstract}
Nenhum vento é favorável para um barco que anda à deriva. E anda à deriva se não existe um projeto concreto de viagem, se não há forma de controlar o barco ou se não estamos a navegar na direcção correcta.
\end{abstract}

Guerra, 2002, p. 289

O problema da indisciplina nas escolas públicas portuguesas não é um fenómeno recente e tem vindo a assumir novas dimensões, devido à frequência com que ocorre, pela visibilidade mediática que tem vindo a ganhar, bem como pela preocupação internacional em assegurar os direitos das crianças. Para Aires (2010), a indisciplina "é um fenómeno intrínseco à sociedade e ao seu sistema de ensino e, dada a sua inevitabilidade, tão antigo como a própria escola" (p. 13).

A problemática da indisciplina nos recreios ${ }^{3}$, especialmente nos dias de chuva, é uma das preocupações principais na vida no Centro Escolar em estudo. A indisciplina apresenta-se como fonte de mal-estar e stress nos diferentes agentes educativos, nos alunos e das relações interpessoais. Lopes (2013) refere que "o desgaste provocado pelo elevado número de actos de indisciplina de baixo impacto...é muito significativo e provoca uma sensação de esgotamento num número não desprezível de professores" (p. 43).

$\mathrm{O}$ tema da indisciplina faz parte de um dos problemas detetados no Projeto Educativo da Escola. O nosso contexto profissional é caraterizado pelas palavras de Estrela (1986), "l'indiscipline scolaire est sans doute un des problémes qui préoccupent davantage ceux qui ont des responsabilités éducatives" (p. 3).

Apesar do estabelecimento de ensino possuir boas instalações, o espaço exterior de recreio é amplo mas sem equipamentos, com apenas um campo de futebol de relva sintética. Os espaços interiores para acolher os alunos durante o recreio, nos dias de chuva, são exíguos, resumindo-se ao hall situado no piso zero e ao ginásio no piso inferior, estando desprovidos de qualquer equipamento ou material.

\footnotetext{
${ }^{3}$ O recreio, segundo Ferreira (1999), é uma palavra derivada de recrear, significando divertimento, prazer. Ainda faz referência ao lugar ou período destinados a se recrear, como um espaço nas escolas ou intervalo livre entre aulas. Os recreios são tempos entre as atividades letivas que podem decorrer em espaços físicos exteriores das escolas ao ar livre ou cobertos, ou no interior das escolas.
} 
A maioria dos professores e assistentes operacionais lida mal com este tipo de situações e quase sempre de forma isolada. Por outro lado, a indisciplina é fundamentalmente uma questão social e é preciso atuar na escola, mas também junto da família, reforçando os comportamentos assertivos. O envolvimento de todos na tentativa de resolução dos problemas é muito importante.

A literatura produzida sobre o tema incide mais na indisciplina em contexto de sala de aula. No entanto, como refere Pereira (2002), é importante dedicar “...um cuidado especial à qualidade dos tempos de recreio nos dias de chuva. Nestes dias colocam-se mais problemas uma vez que os alunos se vêm forçados a permanecer dentro do edifício" ( $p$. 160).

Pereira (2002) associa o comportamento das crianças no recreio ao desenvolvimento. Os recreios escolares podem constituir-se espaços de socialização e de comportamentos assertivos, evitando e prevenindo os comportamentos agressivos entre pares. No entanto, a investigação levada a cabo por Whitney e Smith (1993), mostra-nos que nas 24 escolas estudadas o recreio foi o local onde ocorreram práticas de agressão com mais frequência, especialmente nas escolas do primeiro ciclo. Segundo Pelegrini (1995, cit. por Pereira, 1997), ser agressivo em idades muito baixas pode indiciar futuras crianças agressoras. Assim, as interações que se desenvolvem numa escola com estes níveis de ensino, pela tenra idade dos alunos, requerem uma maior supervisão e uma atitude preventiva.

Atendendo a essa preocupação, a primeira parte do presente artigo faz uma incursão pela literatura sobre a indisciplina, as principais causas e as estratégias para a sua prevenção ou resolução.

A segunda parte é composta pela descrição do projeto, que tem como objetivo prevenir e reduzir a indisciplina nesta faixa etária e mais tarde o bullying, bem como pela apresentação e discussão dos resultados. "Urge laborar, sob pena de os comportamentos inadequados dos alunos evoluírem para formas várias de violência, com resultados académicos devastadores" (Damião, 2013, p. 9).

\section{OLHARES SOBRE A INDISCIPLINA}

Poucos temas têm mobilizado tanto a atenção dos professores do primeiro ciclo do ensino básico como o da indisciplina. Podemos afirmar que este tema é um fenómeno que atravessa a história da educação, podendo-se perceber uma preocupação desde Platão a Aristóteles. As "Confissões" de Sto. Agostinho mostram como a indisciplina dos alunos é perturbadora, originando nos agentes educativos sentimentos de impotência, abatimento e desmotivação. Coménio (1985), pedagogo do século XVII, fez a ilustração de que "uma escola sem disciplina é um 
moinho sem água" (p. 401). Conclui-se, assim, que indisciplina sempre houve ao longo dos tempos.

Contudo, atualmente, as suas manifestações são mais significativas e parecem estar a aumentar. Estas mudanças podem ser explicadas pela democratização do ensino, a consequente massificação das escolas com a inerente heterogeneidade social, as alterações nas estruturas familiares e a influência dos meios de comunicação social.

Os problemas comportamentais e de indisciplina, segundo Lopes e Rutherford (2001), "são normalmente apresentados como competências dos alunos, ou seja, como comportamentos que estes exibem nas escolas e que colidem com os objetivos fundamentais do ensino" (p. 17). Para estes autores, a indisciplina "não implica a existência de agressões intencionais, com clara violação dos direitos de terceiros" mas tende a "ser representada por comportamentos de baixa intensidade mas de elevada frequência" (p. 20).

Veiga (2007) afirma que "por indisciplina entende-se a transgressão das normas escolares, prejudicando as condições de aprendizagem, o ambiente de ensino ou o relacionamento das pessoas na escola" (p. 15).

Para Estrela (1994), "o conceito de indisciplina relaciona-se intimamente com o de disciplina e tende normalmente a ser definido pela sua negação ou privação ou pela desordem proveniente da quebra das regras estabelecidas" (p. 17).

\subsection{Fatores desencadeadores de indisciplina e estratégias de diminuição e prevenção}

Eventos de indisciplina costumam ter génese em múltiplos fatores. A fim de os sistematizar, as causas podem ser externas ou internas à escola. Entre as primeiras encontramos, por exemplo, o ambiente familiar, a influência exercida pelos meios de comunicação e a violência social. As causas encontradas no interior da escola, por sua vez, incluem o ambiente escolar, as condições de ensino e aprendizagem, os espaços e equipamentos disponíveis (Amado \& Freire, 2002; Estrela, 1994; Pereira, 2005). Estrela (1994) cita algumas tais como “...falta de equipamentos didáticos adequados... pessoal auxiliar subqualificado" (p. 11). Pereira (1997) refere-se aos espaços de recreio em Portugal como sendo espaços em que a supervisão é reduzida ou inexistente.

Como o nosso estudo se focaliza na indisciplina nos recreios, especialmente nos dias de chuva, direcionámos a nossa pesquisa para as causas da indisciplina e possíveis estratégias para a sua minimização, neste contexto específico. Vários estudos indicam que a indisciplina no recreio está associada a diversos fatores: espaços exíguos, ausência de supervisão, falta de competências sociais e comunicacionais, espaços 
vazios com poucas oportunidades de jogo, poucos espaços ajardinados (Neto, 2003; Pereira, 2002; Pereira, Neto, \& Smith, 1997; Pereira, Neto, Smith, \& Angulo, 2002). É do conhecimento geral, que em algumas escolas, os espaços de recreio são desertos, pouco interessantes e pouco variados.

A literatura refere e aprofunda as estratégias a ter em conta para a prevenção e/ou diminuição da indisciplina, como por exemplo, melhoramento dos recreios escolares exteriores; criação de espaços interiores de recreio; aquisição de material lúdico-desportivo; gestão e dinamização dos espaços e equipamentos (Marques, Neto, \& Pereira, 2001; Pereira, Neto, \& Smith, 1997; Pereira, Neto, Smith, \& Ângulo, 2002).

\subsection{A gestão e dinamização de espaços e equipamentos do recreio escolar}

Para Pereira (2002), "uma boa imagem de escola e um bom clima não é possível se a escola não possuir espaços de recreio agradáveis" (p. 98). Neste contexto, Sampaio (1996) refere que "os espaços são muito importantes nas escolas. Tal como em nossa casa procuramos, sempre que possível, melhorar o seu aspecto para que nos sintamos melhor, também a escola necessita de ser um local minimamente agradável para que as pessoas se sintam lá bem" (p. 17).

No intuito de dar qualidade aos espaços de recreio, Pereira (2002) considera que "é indispensável equipar os espaços e dar acesso à utilização de pequenos equipamentos nos recreios e incentivar as crianças a trazer os seus próprios equipamentos portáteis (cordas, elásticos, bolas, piões, etc.), sobretudo jogos que possibilitem a cooperação entre as crianças" (p. 190).

Nos dias de chuva a indisciplina pode agravar-se por falta de espaços cobertos. No entanto, problemas de infraestruturas não podem ser óbices. É preciso encontrar alternativas que sejam agradáveis e funcionais, como por exemplo, adaptar espaços e criar uma ludoteca (Pereira, 2002).

A função da educação é, fundamentalmente, transmitir os valores de uma cultura e socializar indivíduos para se tornarem praticantes da cidadania. É nos recreios escolares que os alunos aprendem mais sobre as relações em grupo: decidem com quem conversar, de quem se aproximar, onde e como brincar, aprendem a ceder lugar ao outro, a esperar pela sua vez na roda de amigos para falar, pedir e dar licença e a se desculpar. Assim, o recreio apresenta um amplo campo de oportunidades para o desenvolvimento de valores, atitudes, influenciando a socialização e a aprendizagem de comportamentos assertivos. Como refere Pereira (2005), o jogo tem consigo o poder de mudar a escola, sendo que através dele a 
criança se socializa, aprende as normas e a noção de limite. A Convenção Internacional dos Direitos da Criança (artigo $31^{\circ}$ ) consagra o direito da criança ao jogo.

No entanto, e do ponto de vista de Neto (1997), são cada vez mais limitadas as oportunidades de espaço para brincar e, inclusive, a fraca qualidade do espaço e dos equipamentos dos recreios nas escolas condicionam largamente as atividades de jogo livre nos intervalos.

A convivência entre alunos durante esse tempo livre é um bom termómetro do clima escolar. Mais do que controlar a indisciplina, a escola deve preocupar-se com a sua prevenção, uma vez que os processos corretivos têm uma eficácia reduzida (Amado, 2000; Amado \& Freire, 2009; Lopes, 2009; Menezes, 2003; Pereira, 2005).

Ainda neste âmbito, uma outra razão que poderá estar na base da ocorrência de indisciplina nas escolas pode ser a ineficaz supervisão dos recreios escolares. Pereira (2002), no seu trabalho sobre o estudo e prevenção de práticas educativas entre crianças, diz-nos que os supervisores "estejam atentos aos potenciais problemas, comuniquem sobre eles e em conjunto com os professores e a direção encontrem as soluções possíveis. Pessoas que respeitem os alunos e se façam respeitar, que saibam ouvir os alunos e resolver com eles os seus problemas" ( $p$. 309). Olweus (1998) estabelece uma relação entre a presença de professores e a quantidade de problemas de agressão na escola. A um maior número de professores a vigiar os recreios durante os intervalos, corresponde uma descida dos incidentes relacionados com a indisciplina.

Os assistentes operacionais, muitas vezes, são insuficientes para o número de alunos e espaços, alguns sem experiência e sem formação adequada. Outras vezes são eles que estão na base dos problemas, como expõe Pereira (2005), "vivem ... momentos difíceis na escola, muitas vezes devido a uma má gestão do poder (tolerância excessiva ou prepotência) que, sendo percebida pelos alunos, os leva a não acatarem ordens ou a reagirem de forma agressiva" (p. 5). A supervisão no sentido de prevenir a indisciplina deverá ser implementada apesar desta medida, por si só, poder ser insuficiente.

\subsection{A formação}

Não descurando a importância da formação dos docentes nesta área, Domingues (1995) relata que "aos funcionários é atribuído o papel de educadores morais nos espaços não lectivos. Contudo, eles raramente manifestam possuir uma formação adequada ao desempenho deste papel" (p. 91). É importantíssimo investir na sua formação, para se conseguir fazer deles uma mais-valia para as escolas. $\mathrm{O}$ assistente operacional ativo é precioso nas situações de conflito, de aprendizagem e de organização de 
jogos e brincadeiras. Sobre o seu papel e apoiando-nos em investigações sobre o estudo e prevenção das práticas agressivas, devem colaborar na educação dos alunos, apoiar as crianças que não sabem brincar com os outros ajudando a sua integração nos grupos e acompanhar as crianças que ficam sozinhas no recreio, evitando o seu isolamento (Marques, Neto, \& Pereira, 2001; Pereira, 2002).

\subsection{A definição de regras}

A convivência em grupo pressupõe o cumprimento de regras que norteiam as relações e a escola não foge a essa necessidade, para orientar o seu funcionamento e o convívio entre pares. Assim, falar de disciplina implica falar de regras. Diversos autores referem ser indispensável um sistema de regras bem definidas, a fim de permitir ao aluno saber o que se espera dele (Amado, 2001; Estrela, 1994). Devem ser claras e amplamente disseminadas.

Sampaio (1996) identifica como um dos problemas fulcrais a disparidade e falta de homogeneidade das regras estabelecidas e afirma que "não pode, pois, haver controlo disciplinar sem regras. Mas que espécie de regras podem existir numa escola? Quem as elabora?" (p. 13).

Normalmente surgem no início do ano letivo e como referem Amado e Freire (2002), "raramente são dadas justificações para as regras ou sequer é feita qualquer discussão ou reflexão conjunta com os alunos, de modo a minimizar o seu carácter arbitrário" (p. 16). As regras não devem ser impostas. O levantamento das regras deve ser feito de modo a que as crianças sintam a sua necessidade, que são para o seu bem e para o melhoramento dos seus tempos de recreio. Pereira (2002), no seu estudo sobre prevenção das práticas agressivas entre crianças, refere que se deve “...discutir e definir os comportamentos desejáveis dos alunos em todo o espaço escolar, na sala de aula ou no recreio" (p. 191).

$\mathrm{Na}$ esteira de muitos investigadores, defendemos a importância das regras e que devem ser construídas por todos, incluindo os alunos, como forma de prevenção às situações de indisciplina, num verdadeiro processo de democratização da escola, ou seja, de baixo para cima e de dentro para fora (Guerra, 2002; Jarez, 2002; Sampaio, 1996).

Os alunos indisciplinados são afetados por não se regerem por regras básicas e afetam os colegas bem comportados, podendo até tornarem-se vítimas dos primeiros (Damião, 2013). Espelage (2013) destaca a necessidade de na definição de regras, procurarmos abordar o lado positivo, incentivando a amizade, as boas maneiras e a colaboração, a fim de promover comportamentos pró-sociais. Essa meta só pode ser alcançada com a colaboração da família. 


\subsection{A cooperação entre a escola e o meio}

Vários estudos citados por Estrela e Amado (2000) referem a importância das iniciativas da escola promotoras de comunicação regular e frequente com o meio, com o objetivo de envolver as famílias, as associações e o poder local nos projetos educativos a desenvolver dentro ou fora da escola. Por outro lado, os mesmos autores referem outros estudos (Henriot-Van Zanten, 1988; Bonafé-Schmitt, 1997) que revelam que a articulação entre a escola e o meio não é fácil.

Cousin (1998, cit. por Lima, 2008) refere que "o interesse dos [pais] não se limita unicamente à questão do sucesso [académico]. Existe também uma preocupação com o bem-estar, a qualidade de acolhimento, o ambiente e os modos de regulação dos comportamentos" (pp. 359-360).

Sobre as causas externas, a escola pouco pode fazer para as solucionar, no entanto, precisa de estabelecer pontes com a família, através da informação e do apelo à sua participação (Macbeath, Schratz, Meuret, \& Jakobsen, 2005; Sebastião, Alves, Campos, \& Correia, 2007). Disso depende o sucesso de qualquer projeto de intervenção no campo disciplinar (Amado \& Freire, 2002). Guerra (2001) chama a isso de permeabilidade e Amado (2001) fala da "eficácia do ethos incorporativo...e das vantagens da responsabilidade colectiva...em torno destes problemas" (p. 163).

\section{METODOLOGIA}

\subsection{Objetivos}

No contexto da literatura revista, este projeto apresentou os seguintes objetivos:

1. Diagnosticar carências, deficiências, situações e comportamentos nas escolas potenciadoras de indisciplina;

2. Promover atitudes de cidadania e respeito pelos outros;

3. Desenvolver, com as crianças/alunos, comunidade escolar e parceiros atividades diversificadas e significativas para os participantes, relativamente à problemática identificada;

4. Contribuir para a melhoria das relações e da convivência entre crianças/alunos, professores, funcionários e famílias, através do envolvimento e da participação ativa de todos estes agentes;

5. Articular com as crianças/alunos, a comunidade educativa e parceiros para responder às necessidades diagnosticadas;

6. Promover intervenientes reflexivos, através de diálogos, questionários e formação. 


\subsection{Tipo de investigação e participantes}

Privilegiámos uma metodologia de investigação-ação, com a elaboração de um projeto, no sentido de dar respostas aos problemas identificados (Menezes, 2007).

Participaram no projeto 12 professores titulares de turma, 14 professores das atividades de enriquecimento curricular e 14 assistentes operacionais. O Centro Escolar, implantado no distrito de Viseu, era frequentado por 261 crianças/alunos da educação pré-escolar e do primeiro ciclo do ensino básico no ano letivo 2013-2014.

Colaboraram ainda a equipa de saúde escolar do Centro de Saúde, a Biblioteca Escolar, a Autarquia, empresas locais e os pais/encarregados de educação.

\subsection{Técnicas e instrumentos de investigação}

O diagnóstico da situação foi realizado utilizando diferentes métodos. Concordamos com Amado (2001) quando refere que "são muitos os autores que advogam a necessidade e as vantagens de alguma diversidade metodológica na colheita de dados" (p. 199).

Começámos por centrar a nossa lente na análise do Projeto Educativo e do Regulamento Interno da Escola. Foi, igualmente, objeto de análise o Relatório-Síntese da Inspeção Geral da Educação e Ciência, que nos forneceu uma visão externa sobre as causas do problema.

Recorremos a instrumentos e metodologias de observação naturalista (Estrela, 1984). Assim, durante uma semana de chuva e em diferentes tempos de intervalos (antes, entre e após as atividades letivas), fizemos um conjunto de registos de incidentes críticos. O recreio coberto e os alunos constituíram-se as nossas unidades de observação, a partir das quais registámos as sequências comportamentais.

Contudo, para ter um diagnóstico ainda mais fidedigno, pois segundo Guerra (2001), "quando o diagnóstico é mal feito, as soluções são inevitavelmente deficientes" (p. 11), elaborámos um questionário destinado a todos os agentes educativos. Pretendia-se saber a opinião da comunidade escolar sobre o fenómeno em estudo, tipificar os comportamentos e as causas.

No final do projeto foi realizado um inquérito por questionário aos assistentes operacionais e outro aos docentes. No primeiro caso, pretendia-se que avaliassem os comportamentos dos alunos. No segundo caso, os docentes avaliaram a participação das turmas nas atividades desenvolvidas.

A utilização destas técnicas e instrumentos de avaliação permitiu-nos cumprir de forma rigorosa o primeiro objetivo do projeto e contribuiu 
significativamente para a promoção de intervenientes reflexivos, conforme preconizado no último objetivo.

\subsection{Procedimentos}

$\mathrm{O}$ projeto integrou quatro vertentes dominantes: o melhoramento dos recreios escolares, reestruturando-os e apetrechando-os com materiais lúdicos/didáticos; a supervisão/animação dos espaços e tempos livres dos alunos, com a formação dos agentes educativos; o estabelecimento de regras uniformes e o envolvimento de toda a comunidade educativa e parceiros. O projeto foi implementado entre fevereiro e junho de 2014 e foi apresentado à comunidade educativa e parceiros através de reuniões. Os alunos tiveram o primeiro contato e conhecimento do projeto, através do respetivo professor com a primeira atividade, nomeadamente o visionamento do filme sobre os seus comportamentos nos recreios nos dias de chuva.

Um dos obstáculos à disciplina identificado foi a falta de regras uniformes. Agiu-se de acordo com os estudos efetuados e foram construídas regras com a participação dos alunos (Amado \& Freire, 2002; Pereira, 2002; Sampaio, 1996).

O visionamento do filme sobre os comportamentos dos alunos, referido anteriormente, tinha como objetivo envolvê-los na definição e elaboração das regras. Através de debate em assembleia de turma, os alunos identificaram as atitudes e comportamentos incorretos. Após a identificação e discussão das atitudes a promover para o melhoramento dos seus tempos de recreio, partiram para a elaboração de desenhos com regras claras, simples, fundamentais e positivas, que Short e colaboradores chamam "regras das regras" (1994, cit. em Amado, 2001, p. 162). Conseguimos a envolvência de todos os alunos de acordo com o terceiro objetivo. Paralelamente, a equipa do projeto construiu cartazes alusivos a boas maneiras, baseados nas regras definidas pelos alunos, que passaram por todas as salas a fim de ser feita uma sensibilização para o seu cumprimento, sendo posteriormente afixados nos corredores de acesso às salas de aula.

Outro dos obstáculos à indisciplina identificado foi a falta de equipamentos e espaços físicos cobertos. Neste sentido, foi criada uma ludoteca numa sala de aula devoluta, com jogos, filmes, livros, material de expressão plástica e musical. Os jogos e os livros oferecidos pelos pais foram aí colocados. Cada turma elaborou jogos. A decoração do espaço esteve a cargo da comunidade escolar. Construiu-se um acervo lúdico de acordo com a faixa etária e com o contributo de toda a comunidade educativa, constituindo-se outra das estratégias para o cumprimento dos terceiro e quinto objetivos. 
Outra estratégia foi a criação de um espaço agradável no hall da entrada, que apelasse à tranquilidade, à leitura e ao jogo. No exterior foi fomentada a plantação de árvores no dia da árvore, com a colaboração dos sapadores florestais e o desenho de jogos tradicionais no chão, como "a macaca", "o galo" e "os números".

No dia da criança foi elaborado um painel no qual se afixaram alguns dos "desejos" para a escola, muitos deles articulados com os valores promovidos pelo projeto, tais como solidariedade, respeito, amizade, paz....

Esta fase do projeto incluiu ainda a formação dos alunos. Para o efeito foi criado um "banco" de histórias em formato digital, uma vez que todas as salas de aulas têm quadro interativo, com o objetivo de trabalhar os valores nas aulas de educação para a cidadania.

A formação dos professores e dos funcionários foi realizada com a colaboração de parceiros (Carvalho et al., 2009/2010). Os professores da atividade física e desportiva realizaram um workshop sobre jogos tradicionais para professores e funcionários. No mesmo dia, realizou-se a formação sobre primeiros socorros, pela equipa de saúde escolar do Centro de Saúde.

Procurámos desenvolver um projeto colaborativo, com ênfase na formulação conjunta de estratégias de resolução. Entre outras, constituímos uma equipa de voluntários, responsável pelo projeto que incluía um representante da educação pré-escolar, um de cada ano de escolaridade do primeiro ciclo, a coordenadora de estabelecimento e a professora bibliotecária. Esta equipa coordenou as medidas de intervenção e avaliação e elaborou diversos materiais.

A equipa do projeto foi tendo reuniões com regularidade a fim de aferir as atividades desenvolvidas e a sua monitorização, criando igualmente as grelhas de avaliação. As avaliações foram realizadas através das observações, de fotografias sobre a utilização dos espaços e materiais e de questionários aos agentes educativos.

Foi importante divulgar as medidas implementadas, os resultados obtidos, através do blog criado, sendo uma ferramenta importante para o efeito.

\section{APRESENTAÇÃO E DISCUSSÃO DOS RESULTADOS}

Após a análise do Projeto Educativo e do Regulamento Interno da Escola, verificámos que o problema da indisciplina é identificado e as medidas a implementar são as constantes da legislação específica. $\mathrm{O}$ Relatório-Síntese da Inspeção Geral da Educação e Ciência concluiu que a "falta de espaços cobertos, durante os intervalos, em dias de intempérie, faz com que os alunos se concentrem nos corredores, resultando daí 
elevados níveis de ruído" (p. 7), sendo por isso apontado como um "aspeto negativo" (p. 9). O mesmo relatório regista ainda falta de equipamentos lúdicos no recreio, para além do campo de futebol.

A observação naturalista possibilitou-nos observar e registar os comportamentos de indisciplina dos alunos nos diferentes espaços interiores, nos períodos antes, entre e após as aulas, durante uma semana de chuva, apenas possíveis de apreender através da observação (Quivy, 2005).

Na observação das interações ocorridas registámos como ocorrências mais frequentes as agressões aos colegas, tais como murros, pontapés e empurrar; a correria e os gritos. Observaram-se ainda situações de saltar à corda e jogar à bola, conforme o observado no Gráfico 1 .

\section{Gráfico 1}

Registo de incidentes críticos nos espaços interiores

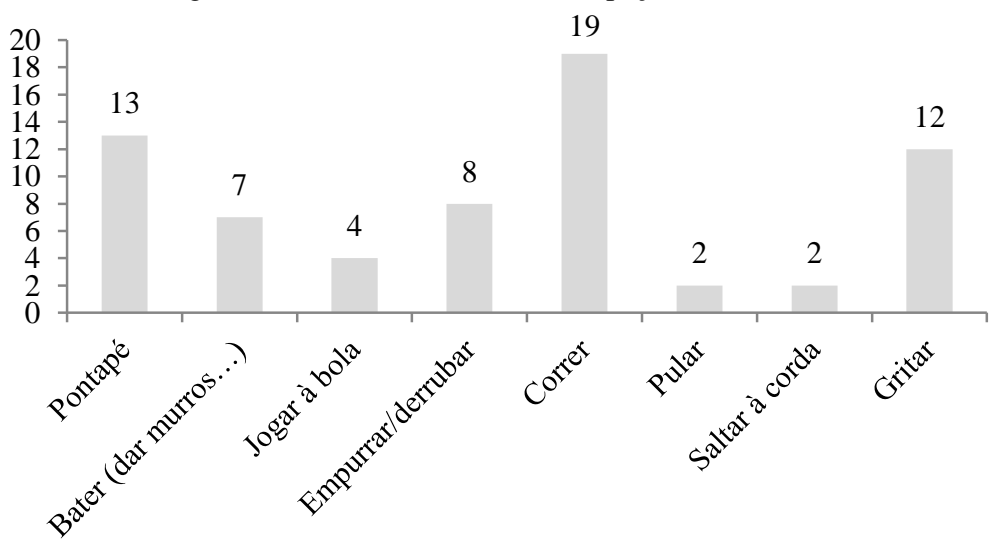

Outras formas de indisciplina, como gozar com os colegas ou os adultos, bem como linguagem imprópria, não nos foi possível detetar na observação, o que atribuímos ao fato de haver sempre muito ruído, movimentação e confusão. Registámos poucas intervenções dos adultos e com reduzida eficácia, uma vez que as crianças obedecem pouco, confirmando a má gestão do poder (tolerância excessiva) referida por Pereira (2005). Quando obedecem é só no momento, para logo de seguida retomarem o comportamento incorreto.

Desta forma, a observação naturalista permitiu detetar os comportamentos e as situações mais frequentes e mais relevantes de indisciplina, que mais tarde deu origem à elaboração do inquérito por questionário aos agentes educativos. Para além do tipo de indisciplina 
pretendíamos também obter informações sobre as causas e envolver a comunidade educativa na procura de soluções.

Os comportamentos agressivos têm várias formas de expressão, como podemos ver no gráfico 2 . Os casos mais comuns de indisciplina identificados são correr no hall e gritar, assinalados por $100 \%$ e $95 \%$ dos agentes educativos, respetivamente. Logo de seguida temos o falar muito alto, não aceitar as ordens dos adultos e agredir os colegas, com valores muito próximos uns dos outros e identificados pela maioria dos inquiridos, oscilando entre $78 \%$ e $68 \%$. É preocupante que nesta faixa etária a agressão tenha valores tão altos, uma vez que ser agressivo em idades muito baixas pode indiciar futuras crianças agressoras (Pellegrini, 1995, cit. em Pereira, 1997). Podemos concluir que estes resultados confirmaram os dados das observações realizadas. O facto de o correr e o gritar apresentarem valores mais altos, na nossa opinião, prende-se com o facto de ser mais fácil de identificar de uma forma empírica.

Gráfico 2

$\mathrm{O}(\mathrm{s})$ caso(s) mais comum(ns) de indisciplina

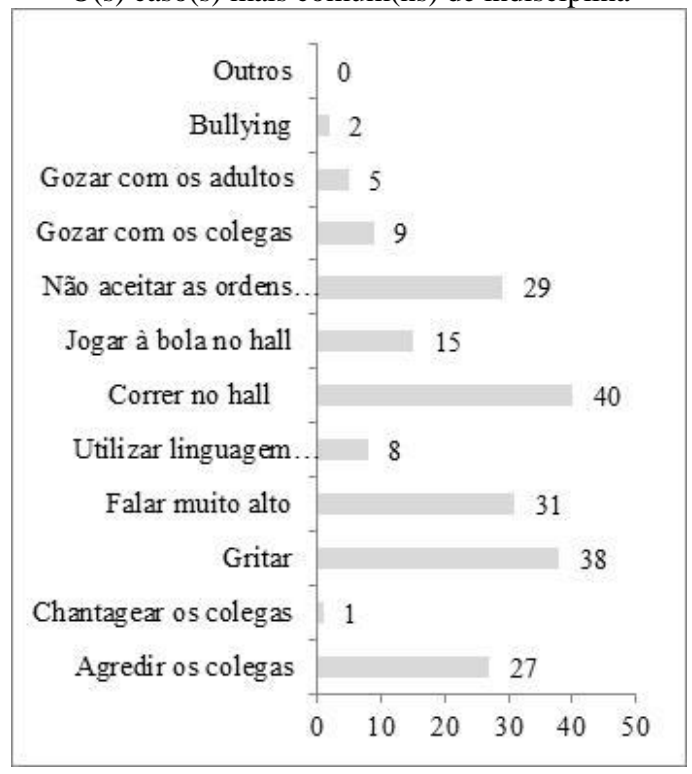

O gráfico 3 evidencia os resultados relativos à atribuição causal da indisciplina. Os principais obstáculos à disciplina identificados pela maioria dos agentes educativos foram fatores associados aos espaços e equipamentos, seguidos da inexistência de regras uniformes e da falta de recursos humanos, indo ao encontro das conclusões efetuadas em diversos estudos e por nós referidos anteriormente (Neto, 2003; Pereira, 
2002; Pereira, Neto, \& Smith, 1997; Pereira, Neto, Smith \& Angulo, 2002).

Gráfico 3

Principais obstáculos à indisciplina

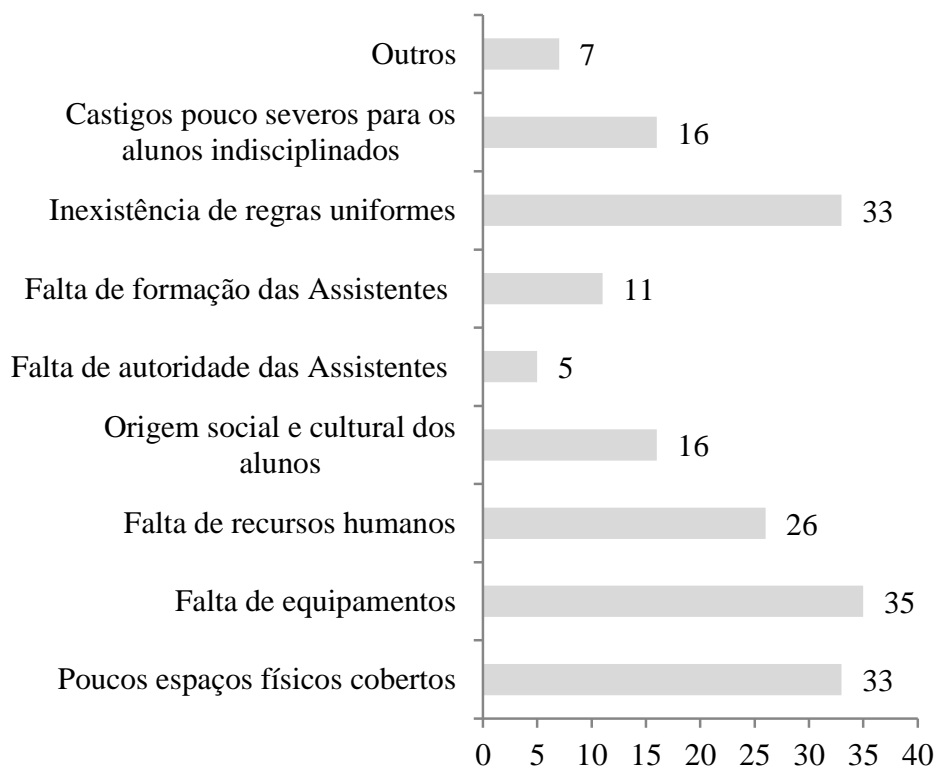

A realização do vídeo para a elaboração de regras levou os alunos a analisar o problema, a expressar opiniões de forma ordeira e a saber participar numa assembleia de escola. Com ele tornou-se mais fácil a definição de regras por parte dos alunos e permitiu que percebessem a necessidade e a importância das mesmas. Conseguimos a envolvência de todos os alunos. A definição de regras simples, claras, positivas, uniformes e contextualizadas para os espaços da escola, permitiu interiorizá-las melhor. Foi possível observar que algumas crianças já começaram a reagir positivamente, por vezes chamando a atenção de alguns colegas.

Apesar de ainda ter decorrido pouco tempo para se sentir uma verdadeira mudança de atitude coletiva, o que já se conseguiu foi fruto da envolvência dos alunos na definição das regras e da sua ampla divulgação, tal como recomendam os investigadores do tema. No entanto, é um ponto que requer continuidade e persistência.

Um dos pontos fundamentais de intervenção teve a ver com a gestão e dinamização de recursos físicos e humanos. Como já referido, problemas 
de infraestruturas não podem ser óbices para que os alunos desenvolvam atividades diferenciadas, que promovam a interação e a convivência entre eles. É possível adaptar espaços dentro da escola que viabilizem atividades no recreio, alternativas que sejam agradáveis e funcionais (ludoteca e espaço do hall decorado).

A criação da ludoteca, local de frequência de cada turma, em sistema rotativo, passou a ser um lugar onde as palavras jogar, ler, pintar, construir e brincar ... não são só palavras, mas uma realidade! Ali, os alunos aprendem a gerir o seu tempo e o espaço, a agir e pensar sobre a sua ação, consigo próprio ou com os outros. O espaço do hall ficou mais acolhedor para os alunos jogarem, lerem e conversarem, impedindo a correria, o ruído e o jogar à bola que eram frequentes neste local.

A disponibilidade ou a quantidade de material didático/lúdico é outro fator ambiente que influencia as relações entre pares. Os materiais (livros e jogos) que os pais, a biblioteca escolar e os alunos construíram/cederam ficaram ao dispor dos alunos.

A avaliação da criação destes espaços e materiais é bastante positiva. Nos dias de chuva permitiu uma menor concentração das crianças no hall da entrada e por consequência um menor índice de agressividade, tal como considerado por Pereira (1997). Tornaram-se áreas de convivência harmoniosa, ampliando os momentos de lazer, de convívio e de interação, próprios deste tempo, deixando de ser monótonos e aborrecidos. Construiu-se um acervo lúdico de acordo com a faixa etária e com o contributo de toda a comunidade educativa, constituindo-se outra das estratégias para o cumprimento dos terceiro e quinto objetivos. A organização do ambiente escolar e de materiais valorizou a brincadeira e o lazer, reconhecidos para o desenvolvimento cognitivo e interação social dos alunos. Assim, confirmamos os estudos que referem estas estratégias como fatores de prevenção da indisciplina entre pares (Pereira, Neto, Smith, \& Ângulo, 2002).

Com a intervenção no recreio exterior aumentámos as oportunidades de jogo e convívio das crianças. Para além de poderem jogar futebol, podem agora praticar diversos jogos com apoio na organização do jogo, por parte dos assistentes operacionais. Através do jogo os alunos estão a entender que têm de cumprir regras e envolve sempre etapas fundamentais para a aprendizagem social do indivíduo. Pereira (2002) afirma que "o jogo é um meio excecional de ajudar a criança a expressarse, permitir testar as capacidades e encorajar a tomada de decisões" (p. 126). Também os professores titulares de turma foram ao recreio realizar os jogos com os seus alunos. Esta dinâmica contribuiu para o cumprimento do terceiro e quarto objetivos. É agradável ver as crianças entretidas com o jogo da macaca, do galo e outros. 
O investimento na formação em contexto de trabalho foi fundamental na vigilância e dinamização dos espaços e tempos de recreio. O workshop sobre os jogos tradicionais permitiu aos assistentes operacionais apreenderem qual o seu papel e como devem intervir nos espaços de recreio, para que estes sejam realmente tempos importantes na realização de aprendizagens. Aprenderam como apoiar as crianças nas brincadeiras e na organização de jogos. Ouvimos expressões tais como "afinal, com coisas simples, podemos entreter os alunos", "isto até é engraçado e os alunos não correm tanto".

A formação realizada pela equipa de saúde sobre primeiros socorros permitiu relembrar atitudes corretas e forneceu algumas novidades em termos de materiais de estancamento de sangue e outro, tornando o tratamento de pequenos acidentes mais fácil.

No questionário para as assistentes operacionais, a fim de serem avaliadas as atitudes e valores respeitados pelos alunos após a implementação do projeto, a maior parte considera como parcialmente atingidos os quatro pontos, sendo o mais conseguido a adesão aos jogos, o que consideramos ser um bom preditor da diminuição da indisciplina.

Gráfico 4

Atitudes e valores respeitados pelos alunos
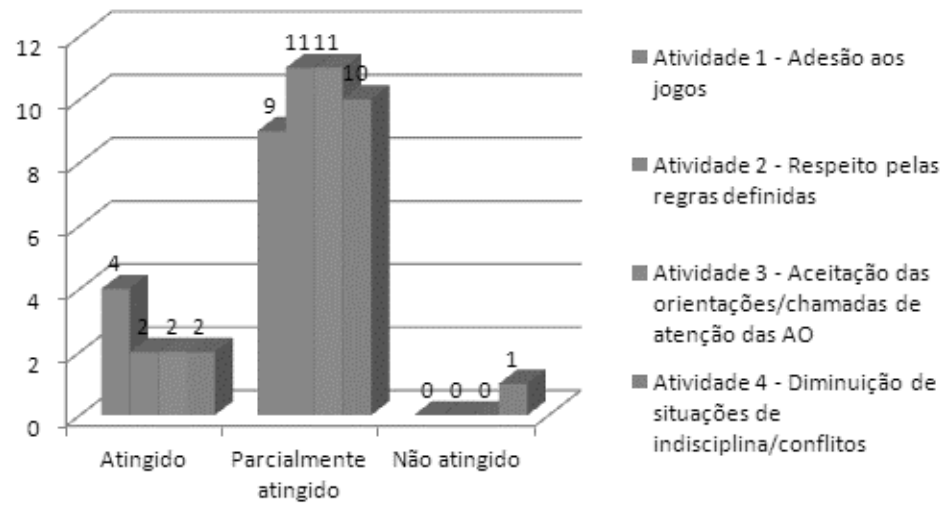

Os docentes avaliaram as atividades realizadas pelas respetivas turmas. Conforme podemos observar no gráfico 5 , foram realizadas por todos os docentes 7 atividades, 1 atividade por 11 docentes, 1 atividade por 10 docentes. As turmas que não participaram em algumas das atividades foram da Educação Pré-Escolar. Só 2 atividades não foram realizadas por todos os docentes. A sua não realização deveu-se 
essencialmente ao projeto só ter começado no segundo período, a realização de exames e outras atividades já planificadas, o que impediu a concretização das duas últimas atividades.

\section{Gráfico 5}

Atividades realizadas pelas turmas

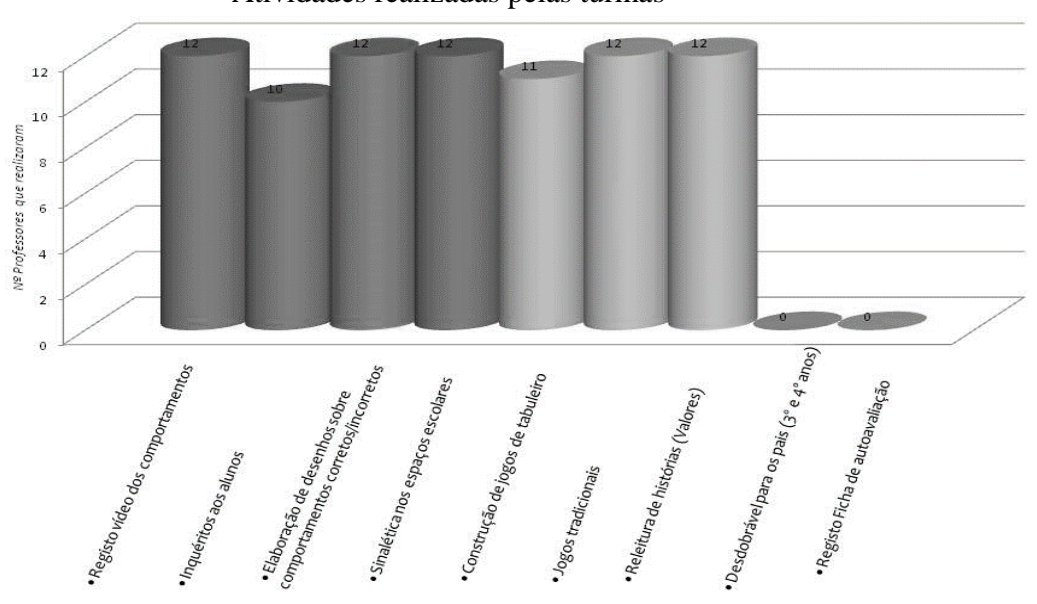

Finalmente, estreitámos as relações entre escola e comunidade. Conseguimos uma articulação e o envolvimento de diferentes parceiros com vista à promoção da qualidade de vida no Centro Escolar e consequente redução e prevenção da indisciplina.

Também os pais corresponderam de uma forma muito positiva ao pedido efetuado pela escola. Num total de 261 pais, responderam 219 e destes $84 \%$ responderam afirmativamente ao pedido de colaboração. Este era um aspeto importante para nós, uma vez que a colaboração da família é decisiva para o sucesso de projetos deste género. Parafraseando o professor Azevedo (2011), "é preciso toda uma comunidade para educar e formar cada pessoa, como diz o célebre ditado africano" (p. 248). Acreditamos que a continuidade do projeto contará com a colaboração dos pais em ordem ascendente.

$\mathrm{O}$ avanço disciplinar na escola parece requerer um alto nível de comunicação e relações democráticas com as comunidades a que atendem (Azevedo, 2011). Por isso, foi de extrema importância a divulgação das atividades através do blog, criado para o efeito. 


\section{CONSIDERAÇÕES FINAIS}

Foi um projeto dinâmico, diversificado, contextualizado, flexível, holístico e sistémico. $\mathrm{O}$ fato de existir um problema serviu de estímulo à implementação do projeto e à sua continuidade. Apesar do projeto ser direcionado a um contexto particular e a uma comunidade específica, foi baseado na literatura sobre o tema. A nível da escola, prevenir a indisciplina nos recreios exige, entre muitos outros aspetos: a definição clara de regras uniformes com os alunos; a criação de espaços agradáveis e equipamentos; uma supervisão eficaz reforçada com formação e o envolvimento dos pais/encarregados de educação e restante comunidade.

De realçar a excelente colaboração dos parceiros, a formação profissional, a intervenção nos espaços escolares, a produção e reutilização de material lúdico-didático. Outro aspeto que importa destacar e o qual constatámos através do projeto desenvolvido, prende-se com a necessidade de incluir os alunos nas decisões da escola, neste caso na definição de regras, num verdadeiro processo de democratização da escola, tornando mais fácil o seu cumprimento.

$\mathrm{O}$ projeto assumiu pertinência, na medida em que, para além de diminuir a indisciplina, contribuiu essencialmente para a prevenção da mesma. Não pretendíamos a solução definitiva do problema, antes refletir sobre ele, organizar um quadro teórico "procurando formas proactivas, preventivas, e por isso eficazes de lidar com o problema da indisciplina" (Lopes, 2013, p. 62).

As estratégias deram resposta às causas da indisciplina diagnosticadas, embora reconheçamos que foram o início de um caminho que precisa de continuar a ser trilhado com perseverança, empenho e dedicação. Numa escola que aprende e se desenvolve "é mais importante saber onde se quer ir que pôr-se a caminho sem rumo. É mais importante saber para onde se caminha que acelerar o passo em direcção a nenhures" (Guerra, 2002, p. 19). Este trabalho de projeto, após ter dado início a uma reflexão e intervenção sobre a indisciplina no Centro Escolar, serviu de base para perspetivar novas reflexões e intervenções devidamente ajustadas à realidade, entrando assim num novo ciclo de espiral da pesquisa-ação.

Há também necessidade de continuar a estreitar as relações entre escola e família. Contudo, concordamos com Azevedo (2011), que para envolver a comunidade "requer um árduo trabalho...uma grande capacidade de diálogo...a disponibilidade para ouvir" (p. 248), mas também acreditamos que sustenta qualquer êxito sério.

Sentimos no terreno as palavras de Guerra (2001) quando diz que "o problema reside no facto de não haver tempos, nem espaços, nem meios para concretizar essa reflexão de uma forma sistematizada e rigorosa" (p. 
107). Por outro lado, o espaço de tempo em que decorreu o projeto foi limitado, impossibilitando a implementação de todas as atividades e consolidação dos comportamentos. Como diz o ditado popular "é preciso dar tempo ao tempo". No entanto, esse fato pode ser visto pelo lado positivo, uma vez que o problema diagnosticado não vai cair no esquecimento. $\mathrm{O}$ problema transformou-se num projeto sistémico e com continuidade no próximo ano letivo.

$\mathrm{Na}$ sequência do nosso projeto pensamos ser apropriado e pertinente recomendar o desenvolvimento de formação em contexto de trabalho, que promova professores reflexivos (Nóvoa, 2002) e que privilegie a autoformação através da metodologia por nós usada (Estrela, 1994). Numa linha preventiva, os planos curriculares na formação inicial dos professores devem contemplar o campo disciplinar (Estrela, 1994; Picado, 2009).

É fundamental que cada escola encontre soluções eficazes para minimizar/prevenir situações de indisciplina. Para implementar um projeto neste âmbito é necessário que a escola reconheça o problema, que o defina como prioridade, procure a envolvência de todos e crie uma equipa de trabalho para monitorizar a intervenção e definir prioridades (Pereira, 2002). No nosso caso podemos dizer que tal como a tartaruga da fábula de La Fontaine, que é lenta e determinada, este projeto deu os primeiros passos. Mas tal como a tartaruga adaptamo-nos ao terreno e já vencemos uma etapa, cientes e determinados que outras se seguirão (Fullan, 2003).

\section{FONTES E BIBLIOGRAFIA}

Aires, L. (2010). Disciplina na sala de aulas - Um guia de boas práticas para professores do $3^{o}$ ciclo do Ensino Básico e Ensino Secundário. Lisboa: Edições Silabo.

Amado, J. (2001). Interacção pedagógica e indisciplina na aula. Porto: Edições ASA.

Amado, J. (2000). A construção da disciplina na escola. Suportes teórico-práticos. Porto: CRIAP/ASA.

Amado, J. S., \& Freire, I. P. (2002). Indisciplina e violência na escola. Compreender para prevenir. Porto: Edições Asa

Amado, J., \& Freire, I. (2009). A(s) indisciplina(s) na escola. Compreender para prevenir. Coimbra: Almedina.

Azevedo, J. (2011). Liberdade e política pública de educação. Ensaio sobre um novo compromisso social pela educação. Vila Nova de Gaia: Fundação Manuel Leão.

Carvalho, M., Taveira, M. C., Carreira, E., Leça, V., Monteiro, M., \& Magalhães, I. (2009/2010). SER+: Programa de promoção do clima 
psicossocial da escola (relatório). Consultado em 10.07.2013 de file:///C:/Users/Bela/Downloads/2Marisa_Carvalho_Clima_Psicossocial_escola\% 20(9).pdf

Coménio, J. (1985). Didáctica Magna. Tradução de Joaquim Ferreira Gomes. Lisboa: Fundação Calouste Gulbenkian.

Damião, H. (2013). Prefácio. In D. Espelage \& J. Lopes (Coord.). Indisciplina na escola (pp. 7-11). Lisboa: Fundação Francisco Manuel dos Santos.

Domingues, I. (1995). Educação hoje - Processos e práticas. Lisboa: Texto Editora.

Espelage, D. (2013). Prevenir a violência juvenil e o bullying através de programas e de modelos de prevenção escolar sócio-emocionais. In D. Espelage \& J. Lopes (Coord.). Indisciplina na escola (pp. 15-37). Lisboa: Fundação Francisco Manuel dos Santos.

Estrela, A. (1984). Teoria e prática de observação de classes. Uma estratégia de formação de professores. Lisboa: Instituto Nacional de Investigação Científica.

Estrela, M. T. (1994). Relação pedagógica, disciplina e indisciplina na aula (2a . ed. aumentada). Porto: Porto Editora.

Estrela, M. T. (1986). Une étude sur l'indiscipline en classe. Lisboa: Instituto Nacional de Investigação Científica.

Estrela, M., \& Amado, J. (2000). Indisciplina, violência e delinquência na escola: uma perspectiva pedagógica. Revista Portuguesa de Pedagogia, Ano XXXIV-1,2,3, 249-271.

Fullan, M. (2003). Liderar numa cultura de mudança. Porto: Edições ASA.

Guerra, S. M. (2002). Entre bastidores. O lado oculto da organização escolar. Porto: Edições ASA.

Guerra, M. A. S. (2001). A escola que aprende. Porto: Edições Asa.

Jarez, X. R. (2002). Educação e conflito - guia para a convivência (Colecção Práticas Educativas). Lisboa: Edições ASA.

Lima, J. Á. (2008). Em busca da boa escola: instituições eficazes e sucesso educativo. Vila Nova de Gaia: Fundação Manuel Leão.

Lopes, J. (2013). A indisciplina em sala de aula. In D. Espelage \& J. Lopes (Coord.). Indisciplina na escola (pp. 41-67). Lisboa: Fundação Francisco Manuel dos Santos.

Lopes, J. (2009). Comportamento, aprendizagem e "ensinagem". Na ordem e desordem na sala de aula. Braga: Psiquilíbrios Edições.

Lopes, J., \& Rutherford, R. (2001). Problemas de comportamento na sala de aula: identificação, avaliação e modificação. Porto: Porto Editora. 
Macbeath, J., Schratz, M., Meuret, D., \& Jakobsen, B. L. (2005). A História de Serena. Viajando rumo a uma Escola melhor. Porto: Edições ASA.

Marques, A. R., Neto, C., \& Pereira, B. O. (2001). Changes in school playground to reduce aggressive behavior. In M. Martinez (Ed.). Prevention and Control of aggression and the impact on its victims (pp. 137-145). New York: Kluwer Academic/Plenum Publishers.

Menezes, I. (2003). A intervenção para a resolução de conflitos ao nível da escola e da comunidade. In M. E. Costa (Coord.). Gestão de conflitos na escola (pp. 257-299). Lisboa: Universidade Aberta.

Menezes, I. (2007). Intervenção comunitária. Uma perspectiva psicológica. Porto: Livpsic.

Neto, C. (1997). Tempo \& espaço de jogo para a criança: rotinas e mudanças sociais. In C. Neto (Coord.). Jogo e o desenvolvimento da criança (pp. 10-22). Lisboa: Edições FMH, Universidade Técnica de Lisboa.

Neto, C. (2003). Entrevista, Semanário Revista Visão n. ${ }^{\circ}$ 553, de 9 de Outubro, pp. 19-21.

Nóvoa, A. (2002). Concepções e práticas de formação contínua de professores. In A. Nóvoa (Coord.). Formação de professores e trabalho pedagógico (pp. 49-66). Lisboa: Universidade de Lisboa.

Olweus D. (1998). Conducta de acosso y amenaza entre escolares (4 ${ }^{\mathrm{a}}$ ed.). Madrid: Morata, S.L.

Pereira, B. (1997). Estudo e prevenção do bullying no contexto escolar Os recreios e as práticas agressivas da criança. Universidade do Minho: Instituto de Estudos da Criança.

Pereira, B. (2002). Para uma escola sem violência: estudo e prevenção das práticas agressivas entre crianças. Lisboa: Fundação Calouste Gulbenkian - Ministério da Ciência e da Tecnologia. Fundação para a Ciência e a Tecnologia.

Pereira, B. (2005). Recreios escolares e prevenção da violência: dos espaços às atividades. Universidade do Minho: Instituto de Estudos da Criança. Consultado em 24.12.2013 de http://repositorium.sdum.uminho.pt/bitstream/1822/3966/1/Recreios\% 20escolares\%20e\%20preven\%C3\%A7\%C3\%A3o\%20da\%20viol\%C3 $\%$ AAncia.pdf

Pereira, B., Neto, C., Smith, P. K., \& Angulo J.C. (2002). Reinventar los espacios de recreo. Prevenir los comportamientos agresivos. Cultura y Educación, 14 (3), 297- 311.

Pereira, B., Neto, C., \& Smith, P.K. (1997). Os espaços de recreio e a prevenção do "bullying" na escola. In C. Neto (Coord.). $O$ jogo e $o$ desenvolvimento da criança (pp. 239-258). Lisboa: Edições FMH. 
Picado, L. (2009). Bullying em Contexto Escolar. Consultado em 30.06.2014, de http://www.psicologia.pt/artigos/textos/A0575.pdf

Quivy, R., \& Campenhoudt, L. V. (2005). Manual de investigação em ciências sociais (4. ${ }^{\mathrm{a}}$ ed.). Lisboa: Gradiva.

Sampaio, D. (1996). Voltei à escola. Lisboa: Editorial Caminho.

Sebastião, J., Alves, M., Campos, J., \& Correia, S. (2007). Violência na escola: mediatização, insegurança e prevenção. Noesis, 68, 50-55.

UNICEF (1989). A Convenção internacional sobre os direitos da criança. Consultado em 10.07.2014 de

https://www.unicef.pt/docs/pdf_publicacoes/convencao_direitos_crianca2 004.pdf

Veiga, F. H. (2007). Indisciplina e violência na escola: Práticas comunicacionais para Professores e Pais ( $3^{\mathrm{a}}$ Ed.). Coimbra: Almedina

Witney, I., \& Smith, P. K. (1993). A survey of the nature and extent of bullying in junior middle and secondary schools. Educational Research, 35 (1), 38-47.

\section{Legislação:}

Lei n. ${ }^{\circ} 51$ de 5 de setembro de 2012 (2012). Diário da República, 1. ${ }^{a}$ Série - N. ${ }^{\circ}$ 172. Lisboa: Ministério da Educação. 